\title{
Analysis of the Negative Daily Temperatures Influence on the Failure Rate of the Water Supply Network
}

\author{
Jakub Żywiec ${ }^{1, *\left(\mathbb{C}, \text { Krzysztof Boryczko }^{1}(\mathbb{D} \text { and Dariusz Kowalski }\right.}{ }^{2}$ \\ 1 Department of Water Supply and Sewerage Systems, Faculty of Civil, Environmental Engineering \\ and Architecture, Rzeszow University of Technology, al. Powstańców Warszawy 6, 35-959 Rzeszów, Poland; \\ kb@prz.edu.pl \\ 2 Faculty of Environmental Engineering, Lublin University of Technology, ul. Nadbystrzycka 40B, \\ 20-618 Lublin, Poland; d.kowalski@pollub.pl \\ * Correspondence: j.zywiec@prz.edu.pl; Tel.: +48-17-865-1427
}

Citation: Żywiec, J.; Boryczko, K.; Kowalski, D. Analysis of the Negative Daily Temperatures Influence on the Failure Rate of the Water Supply Network. Resources 2021, 10, 89. https://doi.org/10.3390/ resources10090089

Academic Editor: Manolis G. Grillakis

Received: 27 May 2021

Accepted: 24 August 2021

Published: 26 August 2021

Publisher's Note: MDPI stays neutral with regard to jurisdictional claims in published maps and institutional affiliations.

Copyright: () 2021 by the authors. Licensee MDPI, Basel, Switzerland. This article is an open access article distributed under the terms and conditions of the Creative Commons Attribution (CC BY) license (https:// creativecommons.org/licenses/by/ $4.0 /)$.

\begin{abstract}
As a part of the critical infrastructure, water supply systems must be characterized by an appropriate level of operational reliability and safety. One of the threats to this is the failure of the water supply network, influenced by many factors, among which we can distinguish internal factors related to the process of designing, construction and system operation, and external factors related to the impact of the environment. The paper presents the influence of negative daily temperature on the failure rate of the water supply network, taking into account the material of the pipes, their diameters, and the cause of failure. The research was carried out on operational data from the period 2004-2018 from the water supply network in a city located in south-eastern Poland. The relationship between the daily temperature and the failure rate of the water supply system has been shown. As the temperature values drop, the failure rate values increase. The biggest influence of the negative daily temperature on the water supply network failure rate is observed for cast iron pipes. PE and PVC pipes are more resistant to the influence of negative temperatures. The most common cause of failure is corrosion and unsealing of the pipes. Pipes with the diameters of 100, 150, 300, 350, and $400 \mathrm{~mm}$ in distribution and main networks turned out to fail most often. These results can be used by water supply companies to limit the influence of factors related to negative daily temperatures on the failure rate of the water supply network.
\end{abstract}

Keywords: daily temperature; failure; water supply system

\section{Introduction}

Water supply systems, due to their belonging to critical infrastructure, must be characterized by an appropriate level of operational reliability and safety $[1,2]$. The reliability of the water supply system is understood as its ability to perform its functions, in accordance with the requirements in terms of its functioning and safety, i.e., providing consumers with water in the right amount, of appropriate quality, under the right pressure, at an acceptable price at any time [3-5]. Currently, the topic of water supply is faced with many problems related to, among the others, the lack of access to water in developing regions, the appearance of new pollutants in tap water (microplastics, pharmaceuticals) and the functioning of the existing and aging water supply systems [1,3,5-10]. Problems related to the operation of existing water supply systems can be effectively solved by appropriate management, taking into account the minimization of water losses, improvement of the quality of the supplied water and increasing the reliability and safety of their operation [1,5-7]. In order to learn about the mechanisms responsible for the reliability and safety of the water supply system functioning, in recent years much research has been done. One of the directions of this research is the water supply network failure analysis [1-7,11-15]. Over the years, many factors that affect the failure rate of the water supply network have been identified $[3,5-7,11,16-19]$. There can be distinguished internal (system) factors: pipe material, 
pipe diameters, age of the system, pressure in the water supply network, flow rate, quality of design, construction and operation of the system, and external (environmental) factors: climate (seasonality, climate change), weather conditions (temperature, rainfall, drought), soil and water conditions (type of soil, frost depth, groundwater level, corrosivity of the soil and groundwater). Research indicates that bigger failure frequency of water supply networks is observed in cold periods due to ground freezing, and in hot and dry periods due to increased water consumption, soil shrinkage, and ground settlements [11,17,18,20-23]. The strongest relationships between the values of failure rate were observed for the factor associated with daily temperature $[11,16-18,24]$. As the temperature drops, an increase in the failure rate values of the water supply network is observed. With regard to internal factors, it was observed that the value of failure rate is higher for smaller diameters and for older pipes $[5,17,18,22]$. AC and steel pipes failed more often in summer, while in winter, it was the cast iron pipes [16-18,21-23,25]. Higher failure rates are observed in pipes with high pressure or pipes exposed to big pressure fluctuations $[18,19]$. There have also been several studies on the impact of climate change on the failure rate of the water supply network $[16,18,20,21,23,24,26,27]$. They indicate that the biggest threat to the functioning of water supply networks will be changes related to the increase in temperature, intensifying hot periods, and drought $[18,21,23]$. The increase in failure rate may occur as a result of the increased demand for water in these periods and, above all, as a result of soil drying out and its shrinkage and settlement [16-18,20,21,23,27]. On the other hand, depending on the direction of climate change, extreme weather phenomena, severe storms, long-term severe frosts may be observed, which have an equally negative impact on the reliability of the water supply network, causing increase of the failure rate values $[16,18,23,24]$.

The aim of the work was to investigate the influence of negative daily temperatures on the failure rate of the water supply network, taking into account internal factors: material and diameter of the pipes and the causes of failure. The results presented in the paper can be used by water supply companies to better manage the water supply network, in particular when planning the development of the network or renovation of existing sections, minimizing the impact of negative temperatures on the factors influencing the failure rate of the water supply network at an early stage of designing and building new network sections.

\section{Materials and Methods}

\subsection{Research Object}

The failure rate analysis was carried out for the water supply network of the city located in south-eastern Poland. The total length of the analyzed water supply network is $1025 \mathrm{~km}$, including the main network $-55 \mathrm{~km}$, distribution network $-605 \mathrm{~km}$, and water supply connections $-365 \mathrm{~km}$. The pipes of the analyzed water supply network are made of the following materials: steel $(244 \mathrm{~km})$, cast iron $(111 \mathrm{~km}), \operatorname{PE}(401 \mathrm{~km}), \operatorname{PVC}(266 \mathrm{~km})$, asbestos-cement $(3 \mathrm{~km})$. The diameters of the water supply lines vary from $25 \mathrm{~mm}$ to $80 \mathrm{~mm}$ for water supply connections, $100 \mathrm{~mm}$ to $250 \mathrm{~mm}$ for the distribution network, and $300 \mathrm{~mm}$ to $1200 \mathrm{~mm}$ for the main network. For the analysis, a database from water company was used, it contained failure data such as: the date of failure, material and diameter of the failed pipe, and the cause of the failure. The data covered the period from 2004 to 2018. During this period, 3859 failure records were collected. The database was supplemented with information on the daily temperature in the analyzed period based on meteorological measurements from the local weather station. By the term daily temperature we understand the average temperature observed at any given day.

\subsection{Research Method}

In the first stage of the research, a failure analysis of the water supply network was carried out based on the failure rate index (1) taking into account the number of network 
failures occurring at the temperature in the range $(t i ; t i+1>$ and the number of days in which the temperature was in this range $[16,24]$.

$$
\lambda_{T(t i ; t i+1>}=\frac{n_{(t i ; t i+1>}}{d_{(t i ; t i+1>}}, \frac{\text { numbers of failures }}{\text { day at given temperature }}
$$

where:

$\lambda_{(t i ; t+1>}$ - the failure rate at a given daily temperature in range $(t i ; t i+1>$,

$n_{(t i ; i+1>}-$ number of failures occurring at daily temperature in range $(t i ; t i+1>$,

$d_{(t i ; t+1>}-$ number of days with daily temperature in range $(t i ; t i+1>$.

The correlation analysis between the value of the failure rate (1) and the daily temperature in a given range was carried out. The minimum number of measurements for the temperature in a given range was determined so that the extreme temperature values, whose frequency of occurring is very low, and for which high failure rate values are observed, did not affect the correlation result. For this purpose, the difference between the value of the average number of measurements in the tested temperature range (including values from $t_{\min }, t_{0}, t_{\max }$ changing every 1 degree), and the value of the standard deviation was determined according to equation:

$$
d_{\text {min }}=d_{\text {avg }}-d_{\sigma}, \text { days }
$$

where:

$d_{\text {avg }}$ - the average number of days per unit temperature range $\left(t_{i} ; t i+1>(103)\right.$,

$d_{\sigma}$ - the standard deviation of the number of days per unit temperature range $\left(t_{i} ; t i+1>(87)\right.$.

A similar approach was used at work [16,24]. The minimum number of measurements is 16 days. For further calculations, only the results of measurements in the temperature ranges $\left(t_{i}, t_{i+1}>\right.$ for which there was observed a minimum of 16 days, was used. The linear regression equation, the Pearson correlation coefficient- $R$ and the coefficient of determination $R^{2}$ were determined. For the obtained results, a correlation significance test was carried out using the T- Student statistic [28]. The null hypothesis was made as: there is no correlation between the failure rate and daily temperature, and an alternative hypothesis: there is a negative correlation between the failure rate and daily temperature. Test parameter $t$ was determined according to Equation (3) [28]:

$$
t=\frac{R \cdot \sqrt{n-2}}{\sqrt{1-R^{2}}}
$$

where:

$R$-the linear correlation coefficient,

$n$-sample size.

In the next stage, the relationship between the material of the pipes that failed and daily temperature was investigated with the use of the failure rate $\lambda_{M}$ according to the Equation (4); the relationship between the cause of failure and daily temperature using the failure rate $\lambda_{C}$ according to the Equation (5) and the relationship between the diameter of failed pipes and daily temperature using the failure rate $\lambda_{D}$ according to Equation (6).

$$
\begin{gathered}
\lambda_{M(t i ; t+1>}=\frac{n_{M(t i ; t i+1>}}{L_{M} \cdot d_{(t i ; t+1>}}, \frac{\text { numbers of failures }}{\mathrm{km} \cdot \text { day at given temperature }} \\
\lambda_{C(t i ; t+1>}=\frac{n_{C(t i ; t+1>}}{d_{(t i ; t+1>}}, \frac{\text { numbers of failures }}{\text { day at given temperature }} \\
\lambda_{D(t i ; t+1>}=\frac{n_{D(t i ; t i+1>}}{L_{N} \cdot d_{(t i ; t+1>}}, \frac{\text { numbers of failures }}{\mathrm{km} \cdot \text { day at given temperature }}
\end{gathered}
$$


where:

$\lambda_{M(t ; i t i+1>}$-the failure rate for pipes of a given material at a given daily temperature in range $(t i ; t i+1>$,

$\lambda_{C(t i t i+1>}$ - the failure rate resulting from a given cause at a given daily temperature in range $(t i ; t i+1>$,

$\lambda_{D(t ; i t i+1>}$ - the failure rate for pipes of a given diameter at a given daily temperature in range $(t i ; t i+1>$,

$n_{M(t i t i+1>}-$ number of failures of pipes made of a given material occurring at daily temperature in range $(t i ; t i+1>$,

$n_{C(t i ; t+1>}$-number of failures resulting from a given cause occurring at daily temperature in range $(t i ; t i+1>$,

$n_{D(t i ; t+1>}$-number of failures of pipes with a given diameter occurring at daily temperature in range $(t i ; t i+1>$,

$d_{(t i ; t+1>}-$ number of days with daily temperature in range $(t i ; t i+1>$,

$L_{M}$ - total pipe length for a given material, $\mathrm{km}$.

$L_{N}$-average pipe length for a given type of network, $\mathrm{km}$.

To determine the effect of negative temperatures on the failure rate of water supply network, for the obtained results, the Pearson correlation coefficient $R$, the coefficient of determination $R^{2}$ were calculated and the linear regression equation was determined. For the correlation analysis results, the correlation significance test was performed in the same way as presented above. The strengths of the determined relationships were determined based on the value of the Pearson correlation coefficient $R$ according to the scale presented in Table 1.

Table 1. Dependency strength scale (based on [28]).

\begin{tabular}{cc}
\hline The Value of the Correlation Coefficient $R$ & The Power of Dependence \\
\hline$<|0.2|$ & no relationship \\
$|0.2|-|0.4|$ & weak dependence \\
$|0.4|-|0.7|$ & moderate dependence \\
$|0.7|-|0.9|$ & strong dependence \\
$|0.9|-|1.0|$ & very strong dependence \\
\hline
\end{tabular}

\section{Results}

In the first step, the failure rate values in the tested temperature range from $-11{ }^{\circ} \mathrm{C}$ to $26^{\circ} \mathrm{C}$, for which the minimum required number of measurements was obtained (16 days) was calculated. The results of these calculations are presented in Supplementary Materials (Table S1). The lowest failure rate values were observed on days with the daily temperature from 10 to $15^{\circ} \mathrm{C}$. The highest values of the failure rate were obtained for negative daily temperatures. It was observed that the number of failures occurring on days with negative temperature is bigger than or equal to the number of days with negative temperature, therefore the failure rate have values above 1 failure per day with a given negative temperature in range $\left(t_{i} ; t_{i+1}>\right.$. This confirms the statement, that there are more failures on days with negative temperatures than on days with positive temperatures.

Figure 1 shows a diagram of the relationship between the failure rate $\lambda_{T(t i ; t+1>}$, and the value of daily temperature. For the presented data, the linear regression equation was determined, the Pearson correlation coefficient- $R$ and the value of the determination coefficient- $R^{2}$ were calculated.

The linear regression equation took the form of $y=-0.0163 x+0.8977$. The negative slope indicates a negative correlation between the examined variables, i.e., the failure rate decreases with increasing temperature. The value of Pearson's correlation coefficient is $R=-0.7870$, and the coefficient of determination $R^{2}=0.6194$. This means that $61.94 \%$ of changes in the failure rate result directly from changes in the daily temperature value.

For the obtained correlation results, the correlation significance test was carried out. The null hypothesis was adopted as: there is no correlation between the examined variables, 
and the alternative hypothesis: there is a negative correlation between the examined variables. Using the relationship (3), the test parameter $t=-7.547$ was determined for the sample size $n=37$. For the adopted significance level $\alpha=0.05$ and $n-2$ degrees of freedom (35), the critical area $(-\infty ;-1.689572>$ was determined. The calculated test parameter t belongs to the critical area, therefore the null hypothesis should be rejected and an alternative hypothesis adopted (there is a negative correlation between the examined variables). Result of the test confirms the statistical significance of the obtained correlation at the confidence level of $95.0 \%$.

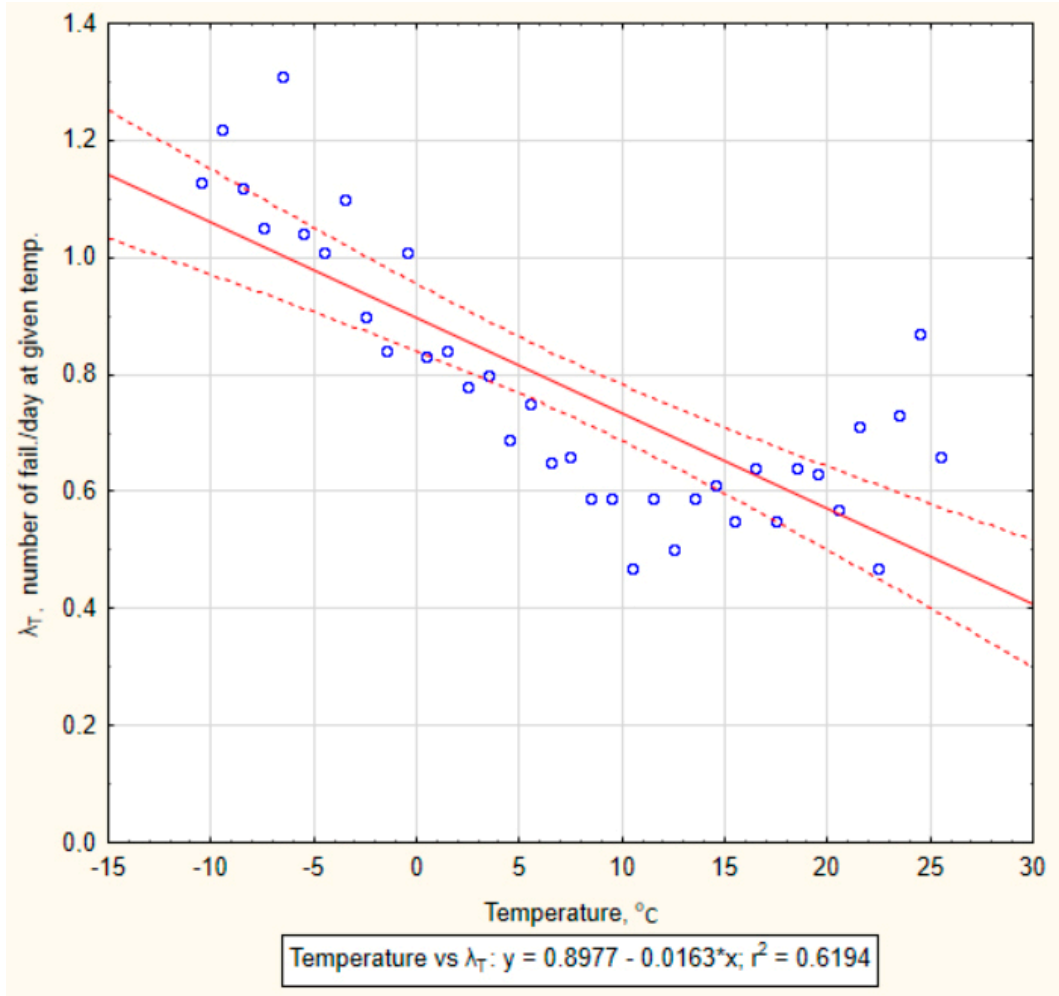

Figure 1. The correlation graph between failure rate and daily temperature.

In the next stage, the relationship between the material of failed pipes and the daily temperature was investigated using the failure rate $\lambda_{M}$ according to the Equation (4). The results of the calculations are presented in Supplementary Materials (Table S2). The biggest total length of pipes in the analyzed network is made of PE $(401 \mathrm{~km})$, then PVC $(266 \mathrm{~km})$, steel $(244 \mathrm{~km})$, cast iron $(111 \mathrm{~km})$, and asbestos-cement $(3 \mathrm{~km})$. The highest values of the failure rate were observed for cast iron pipes (average value $\lambda_{M}=0.0031$ failure $/ \mathrm{km} \cdot$ day), asbestos-cement (average value $\lambda_{M}=0.0017$ failure $/ \mathrm{km} \cdot$ day), and steel pipes (average value $\lambda_{M}=0.0013$ failure $/ \mathrm{km}$.day). Pipes made of plastics materials-PE and PVC are characterized by low values of the failure rate at the average level for PE$\lambda_{M}=0.0002$ failure $/ \mathrm{km} \cdot \mathrm{day}$, and for PVC $-\lambda_{M}=0.0001$ failure $/ \mathrm{km} \cdot$ day. For cast iron pipes, a significantly higher value of the failure rate is observed at temperatures below $0{ }^{\circ} \mathrm{C}$, which indicates that pipes made of this material are the least resistant to negative temperatures. For steel pipes, the values of the failure rate for temperatures below $0{ }^{\circ} \mathrm{C}$ are above average, but the difference is not as visible as in the case of cast iron pipes. A similar dependence can be observed for PE pipes, while the values of the failure rate are on average 6.5 times lower than for steel pipes. Pipes made of PVC at negative temperatures are characterized by a lower failure rate than at positive temperatures. For AC pipes, high values of the failure rate are observed both at very low and very high temperatures.

Figure 2 shows the graphs of the relationship between the failure rate $\lambda_{M}$ and the daily value of temperature for pipes made of individual materials. For the presented 
data, the linear regression equations were determined, the value of the Pearson correlation coefficients- $R$ and the values of the determination coefficients- $R^{2}$ were calculated. For the obtained results the correlation significance test was carried out.
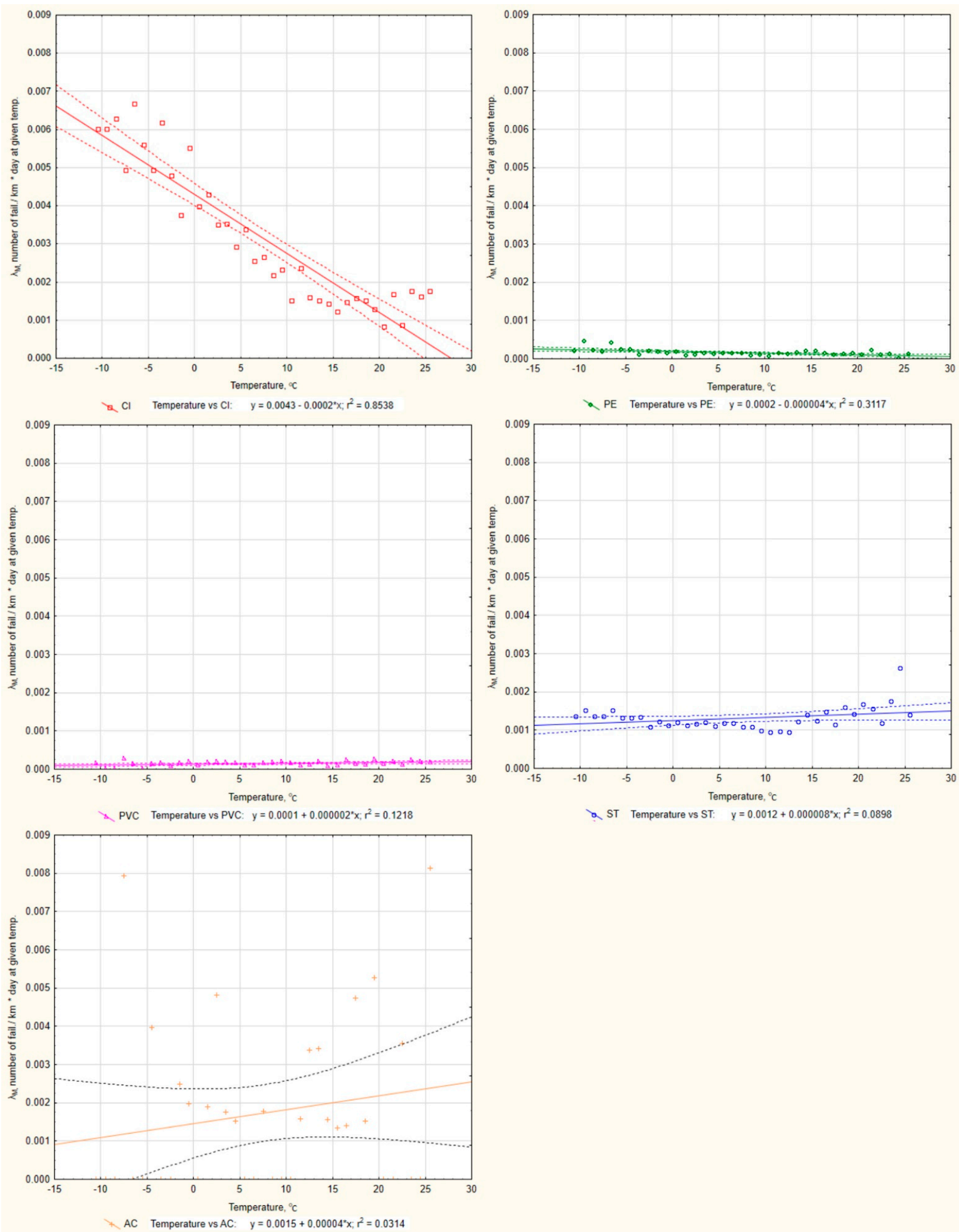

2. ST Temperature vs ST: $\quad y=0.0012+0.000008^{\circ} x, r^{2}=0.0898$

Figure 2. The correlation graphs for the failure rate of pipes made of a given material (CI-cast iron; ST-steel; AC-asbestoscement; PE-polyethylene; PCV-polyvinyl chloride) and the daily temperature. 
The results of the linear regression analysis, correlation coefficients and significance tests are presented in Table 2. For pipes made of cast iron and PE, a negative correlation between the examined variables was shown. This means that with increasing temperature, the value of the failure rate decreases. For pipes made of steel, PVC, and AC, a positive correlation was obtained between the examined variables, which means that the failure rate increases with the temperature increase. For all materials except AC, the $t$ test parameter is within the appropriate critical area (the null hypothesis was assumed to be the lack of correlation between the examined variables, and the existence of a negative or positive correlation was assumed as the alternative hypothesis). Dependencies for steel, cast iron, $\mathrm{PE}$, and PVC pipes should be considered statistically significant with a confidence level of $95.0 \%$.

Table 2. The results of the correlation analysis of the failure rates for pipes made of given material and the daily temperature.

\begin{tabular}{|c|c|c|c|c|c|}
\hline $\begin{array}{c}\text { Pipe } \\
\text { Material }\end{array}$ & $\begin{array}{l}\text { Linear Regression } \\
\text { Equation }\end{array}$ & $\begin{array}{l}\text { Pearson's Correlation } \\
\text { Coefficient } R\end{array}$ & $\begin{array}{l}\text { The Coefficient of } \\
\text { Determination } R^{2}\end{array}$ & $\begin{array}{c}\text { Test } \\
\text { Parameter } t\end{array}$ & Critical Area \\
\hline ST & $y=0.000008 x+0.0012$ & 0.299 & 0.0898 & 1.85 & $<1.689572,+\infty)$ \\
\hline CI & $y=-0.0002 x+0.0043$ & -0.924 & 0.8538 & -14.30 & $(-\infty,-1.689572>$ \\
\hline PE & $y=-0.000004 x+0.0002$ & -0.558 & 0.3117 & -3.98 & $(-\infty,-1.689572>$ \\
\hline PVC & $y=0.000002 x+0.0001$ & 0.349 & 0.1218 & 2.20 & $<1.689572,+\infty)$ \\
\hline $\mathrm{AC}$ & $y=0.00004 x+0.0015$ & 0.177 & 0.0314 & 1.06 & $<1.689572,+\infty)$ \\
\hline
\end{tabular}

The relationship between the cause of the failure and the daily temperature was examined next with the use of the failure rate $\lambda_{C}$ according to the Equation (5). The results of the calculations are presented in Supplementary Materials (Table S3). The pipes most often failed due to corrosion (average value $\lambda_{C}=0.36$ failure/day), then unsealing (average value $\lambda_{C}=0.27$ failure/day), breakage (average $\lambda_{C}=0.10$ failure/day), and cracks (mean value of $\lambda_{C}=0.05$ failure/day).

For unsealing and breakage, a higher value of the failure rate is observed at temperatures below $0{ }^{\circ} \mathrm{C}$. For a crack, the values of the failure rate at negative temperatures are above average, but the difference is not as large as in the case of unsealing and breakage. For corrosion, high values of the failure rate are observed both at very low and very high temperatures.

Figure 3 shows the graphs of the relationship between the failure rate $\lambda_{C}$ and the daily value of temperature for pipes whose failure results from a given cause. For the presented data, the linear regression equations were determined, the value of the Pearson correlation coefficients- $R$ and the values of the determination coefficients- $R^{2}$ were calculated. For the obtained results the correlation significance test was carried out.

The results of linear regression analysis, correlation coefficients and significance tests are presented in Table 3. For pipes whose failure resulted from unsealing, breakage, and cracks, a negative correlation was obtained between the examined variables. This means that with increasing temperature, the value of the failure rate decreases. For the pipes where the failure occurred as a result of corrosion, a positive correlation was obtained between the examined variables, which means that the failure rate increases with the temperature increase. For the cause of the failure: unsealing and breakage, the test parameter $t$ is in the critical area (the null hypothesis was assumed to be the lack of correlation between the studied variables, and the existence of a negative correlation was assumed as the alternative hypothesis). These dependencies should be considered statistically significant with a confidence level of $95.0 \%$. For the causes of corrosion and cracking, the null hypothesis cannot be rejected, the obtained relationships are not statistically significant at the given confidence level. 

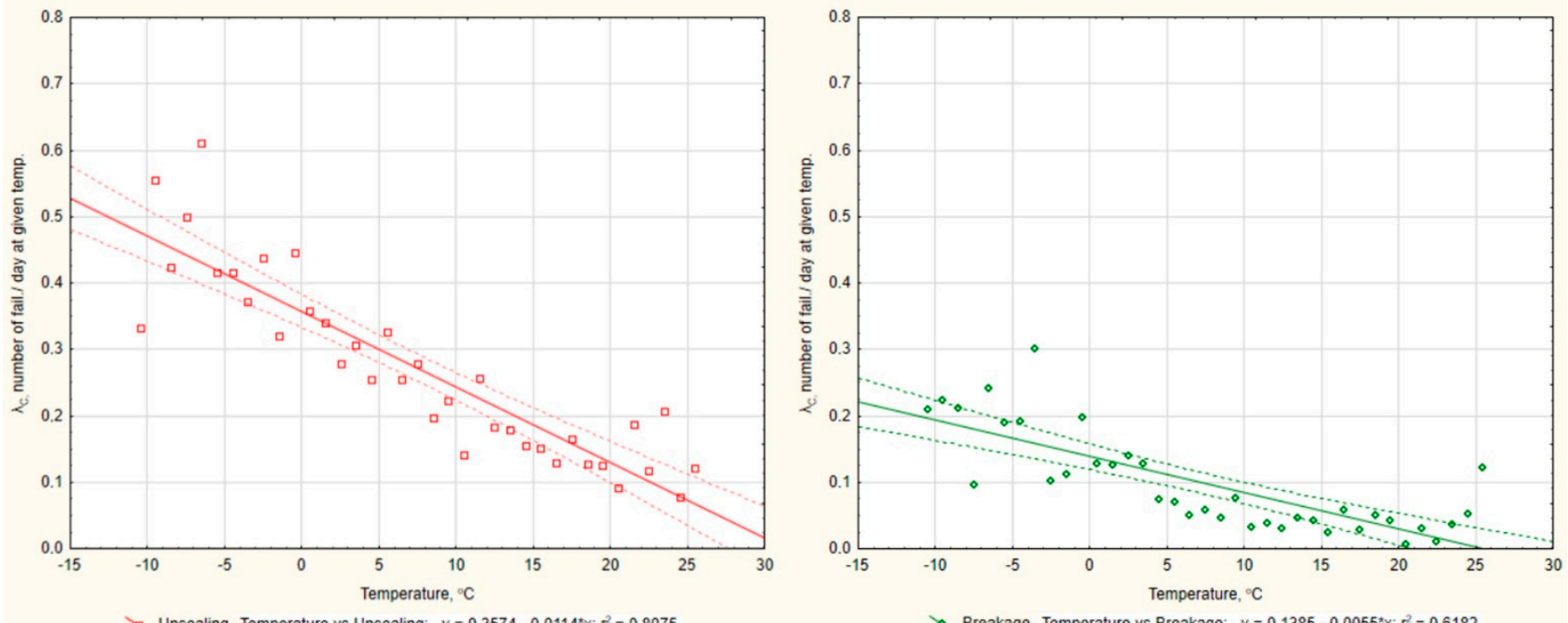

2. Unsealing Temperature vs Unsealing: $y=0.3574-0.0114^{*} x ; r^{2}=0.8075$
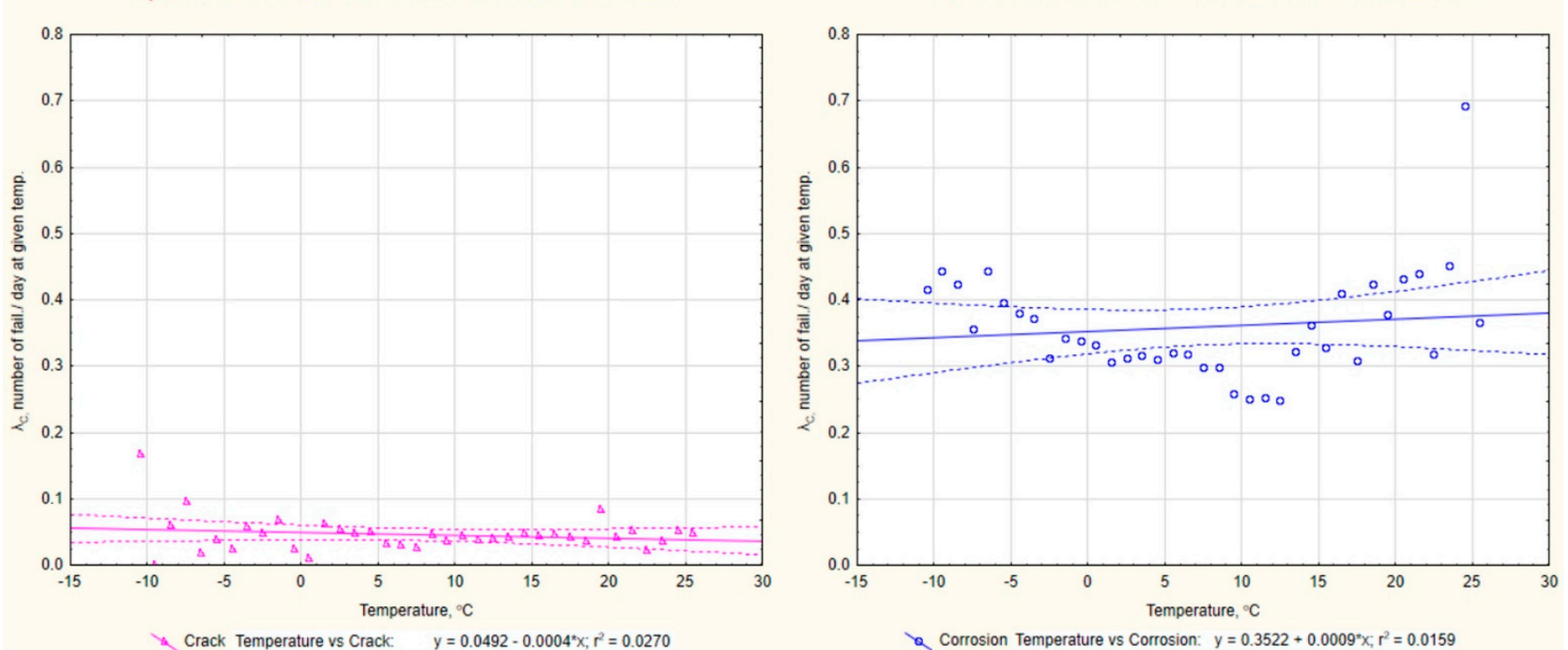

Figure 3. The correlation graphs for the pipe failure rate due to a given cause of failure (unsealing, breakage, crack, corrosion) and the daily temperature.

Table 3. The results of the correlation analysis of the pipe failure rate as a result of a given cause and the daily temperature.

\begin{tabular}{cccccc}
\hline $\begin{array}{c}\text { Failure } \\
\text { Cause }\end{array}$ & $\begin{array}{c}\text { Linear Regression } \\
\text { Equation }\end{array}$ & $\begin{array}{c}\text { Pearson's Correlation } \\
\text { Coefficient } \boldsymbol{R}\end{array}$ & $\begin{array}{c}\text { The Coefficient of } \\
\text { Determination } \boldsymbol{R}^{2}\end{array}$ & $\begin{array}{c}\text { Test } \\
\text { Parameter } \mathbf{t}\end{array}$ & Critical Area \\
\hline corrosion & $\mathrm{y}=0.0009 \mathrm{x}+0.3522$ & 0.126 & 0.0159 & 0.75 & $<1.689572,+\infty)$ \\
unsealing & $\mathrm{y}=-0.0114 \mathrm{x}+0.3574$ & -0.899 & 0.8075 & -12.12 & $(-\infty,-1.689572>$ \\
breakage & $\mathrm{y}=-0.0055 \mathrm{x}+0.1385$ & -0.786 & 0.6182 & -7.53 & $(-\infty,-1.689572>$ \\
crack & $\mathrm{y}=-0.0004 \mathrm{x}+0.0492$ & -0.164 & 0.027 & -0.99 & $(-\infty,-1.689572>$ \\
\hline
\end{tabular}

In the next step, the relationship between the diameter of the failed pipe and the daily temperature was examined using the failure rate $\lambda_{D}$ according to the dependence (6). Due to the lack of detailed data on the lengths of pipes of a particular diameter, the average length of pipes for a given type of network was used. For water supply connections, this length was $L_{N}=365 / 6=60.8 \mathrm{~km}$, for the distribution network $L_{N}=605 / 4=151.3 \mathrm{~km}$, and for the main network $L_{N}=55 / 8=6.9 \mathrm{~km}$. The calculation results are presented in Supplementary Materials (Tables S4-S7) sectioned into the type of network. Among the water supply connections, pipes with a diameter of 80,50 , and $32 \mathrm{~mm}$ were the 
most likely to fail (average value of $\lambda_{D 80 \mathrm{~mm}}=0.0016$ failure $/ \mathrm{km}$ day, average value of $\lambda_{D 50 \mathrm{~mm}}=0.0015$ failure $/ \mathrm{km}$ day, average value of $\lambda_{D 32 \mathrm{~mm}}=0.0015$ failure $/ \mathrm{km}$ day), in the distribution network these were pipes with a diameter of 100 and $150 \mathrm{~mm}$ (average value of $\lambda_{D 100 \mathrm{~mm}}=0.0008$ failure $/ \mathrm{km}$ day, average value of $\lambda_{D 50 \mathrm{~mm}}=0.0007$ failure $/ \mathrm{km}$ day). In the main network, pipes with a diameter of 400,300 , and $500 \mathrm{~mm}$ were most likely to fail (average value of $\lambda_{D 400 \mathrm{~mm}}=0.01025$ failure $/ \mathrm{km}$ day, average value of $\lambda_{D 300 \mathrm{~mm}}=0.00173$ failure $/ \mathrm{km} \cdot$ day, average value of $\lambda_{D 500 \mathrm{~mm}}=0.00156$ failure $/ \mathrm{km}$ day).

For water supply connections, higher values of the failure rate for diameters: 50, 65, and $80 \mathrm{~mm}$ are observed at negative daily temperatures. For distribution network pipes, at negative temperatures, higher values of the failure rate are observed for diameters 100, $150 \mathrm{~mm}$. For the diameter of $200 \mathrm{~mm}$, the values of the failure rate at negative temperatures are above the average, but the difference is not as large as in the case of the diameter of 100 and $150 \mathrm{~mm}$. For main network pipes, higher values of the failure rate are observed at negative temperatures for diameters of 300,350 , and $400 \mathrm{~mm}$, while for a diameter of $400 \mathrm{~mm}$ these values are about six times greater than for a diameter of $300 \mathrm{~mm}$.

Figures 4-7 show the graphs of the relationship between the failure rate $\lambda_{D}$ and the daily value of temperature for the pipes of the examined network with a given diameter, divided by type of network. For the presented data, the linear regression equations were determined, the value of the Pearson correlation coefficients- $R$ and the values of the determination coefficients- $R^{2}$ were calculated. For the obtained results the correlation significance test was carried out.

The results of linear regression analysis, correlation coefficients, and significance tests are presented in Table 4. For pipes with a diameter of 80, 100, 150, 200, 300, 350, $400 \mathrm{~mm}$, a negative correlation was obtained between the examined variables. This means that with increasing temperature, the value of the failure rate decreases. For pipes with a diameter of 25 and 500 , a positive correlation was obtained between the examined variables, which means that the failure rate increases with the temperature increase. For these mentioned diameters, the test parameter $t$ is in the appropriate critical area (the null hypothesis was assumed to be the lack of correlation between the examined variables, and the existence of a negative or positive correlation was assumed as the alternative hypothesis). These dependencies should be considered statistically significant with a confidence level of $95.0 \%$. For diameters of $32,40,50,65,250,450,600,800,1200 \mathrm{~mm}$, the null hypothesis cannot be rejected, the obtained relationships are not statistically significant at the given confidence level.

Table 4. The results of the correlation analysis of the failure rate for pipes with a given diameter and daily temperature.

\begin{tabular}{|c|c|c|c|c|c|}
\hline $\begin{array}{l}\text { Pipe Diameter, } \\
\text { mm }\end{array}$ & $\begin{array}{c}\text { Linear Regression } \\
\text { Equation }\end{array}$ & $\begin{array}{l}\text { Pearson's Correltion } \\
\text { Coefficient } R\end{array}$ & $\begin{array}{l}\text { The Coefficient of } \\
\text { Determination } R^{2}\end{array}$ & $\begin{array}{c}\text { Test } \\
\text { Parameter } t\end{array}$ & Critical Area \\
\hline 25 & $y=1.30 \cdot 10^{-5} x+0.0007$ & 0.338 & 0.1144 & 2.13 & $<1.689572,+\infty)$ \\
\hline 32 & $y=4.62 \cdot 10^{-6} x+0.0014$ & 0.094 & 0.0089 & 0.56 & $<1.689572,+\infty)$ \\
\hline 40 & $y=-8.51 \cdot 10^{-7} x+0.0008$ & -0.026 & 0.0007 & -0.16 & $(-\infty,-1.689572>$ \\
\hline 50 & $y=9.76 \cdot 10^{-7} x+0.0015$ & 0.017 & 0.0003 & 0.10 & $<1.689572,+\infty)$ \\
\hline 65 & $y=-4.10 \cdot 10^{-6} x+0.0003$ & -0.178 & 0.0316 & -1.07 & $(-\infty,-1.689572>$ \\
\hline 80 & $y=-4.70 \cdot 10^{-5} x+0.0019$ & -0.580 & 0.3361 & -4.21 & $(-\infty,-1.689572>$ \\
\hline 100 & $y=-3.30 \cdot 10^{-5} x+0.0011$ & -0.753 & 0.5666 & -6.76 & $(-\infty,-1.689572>$ \\
\hline 150 & $y=-3.78 \cdot 10^{-5} x+0.001$ & -0.852 & 0.7262 & -9.63 & $(-\infty,-1.689572>$ \\
\hline 200 & $y=-7.63 \cdot 10^{-6} x+0.0002$ & -0.529 & 0.2799 & -3.69 & $(-\infty,-1.689572>$ \\
\hline 250 & $y=-1.31 \cdot 10^{-6} x+0.0002$ & -0.116 & 0.0135 & -0.69 & $(-\infty,-1.689572>$ \\
\hline 300 & $y=-9.31 \cdot 10^{-5} x+0.0024$ & -0.470 & 0.2213 & -3.15 & $(-\infty,-1.689572>$ \\
\hline 350 & $y=-6.97 \cdot 10^{-5} x+0.002$ & -0.451 & 0.203 & -2.99 & $(-\infty,-1.689572>$ \\
\hline 400 & $y=-0.0002 x+0.0121$ & -0.574 & 0.33 & -4.15 & $(-\infty,-1.689572>$ \\
\hline 450 & $y=1.13 \cdot 10^{-6} x+9.95 \cdot 10^{-6}$ & 0.109 & 0.0119 & 0.65 & $<1.689572,+\infty)$ \\
\hline 500 & $y=8.53 \cdot 10^{-5} x+0.0009$ & 0.349 & 0.1217 & 2.20 & $<1.689572,+\infty)$ \\
\hline 600 & $y=1.19 \cdot 10^{-6} x+5.38 \cdot 10^{-5}$ & 0.060 & 0.0036 & 0.36 & $<1.689572,+\infty)$ \\
\hline 800 & $y=-4.19 \cdot 10^{-7} x+6.19 \cdot 10^{-5}$ & -0.022 & 0.0005 & -0.13 & $(-\infty,-1.689572>$ \\
\hline 1200 & $y=-3.69 \cdot 10^{-7} x+2.38 \cdot 10^{-5}$ & -0.032 & 0.001 & -0.19 & $(-\infty,-1.689572>$ \\
\hline
\end{tabular}



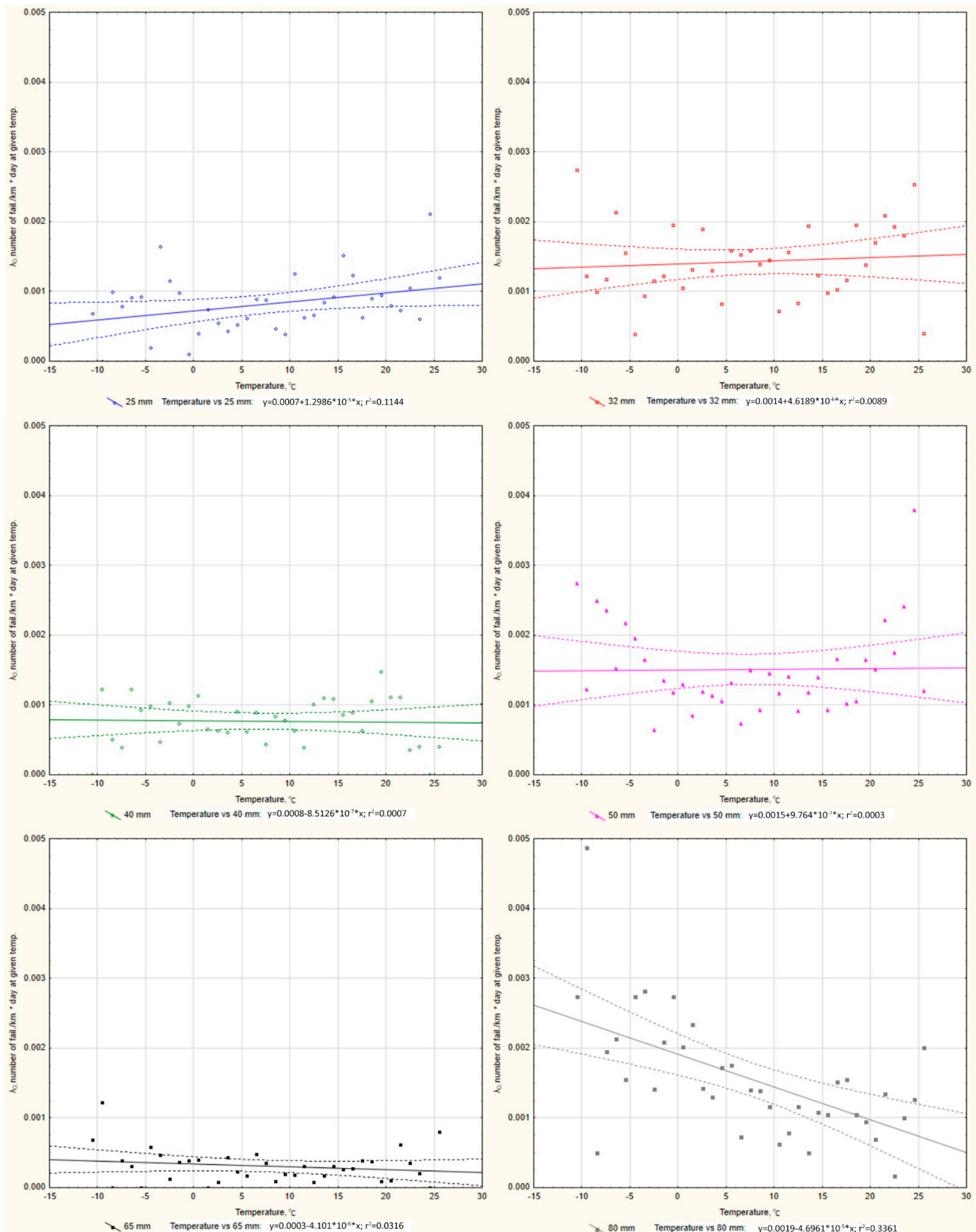

Figure 4. The correlation graphs for the failure rate of water supply connections with a given diameter (25-80 $\mathrm{mm})$ and daily temperature. 

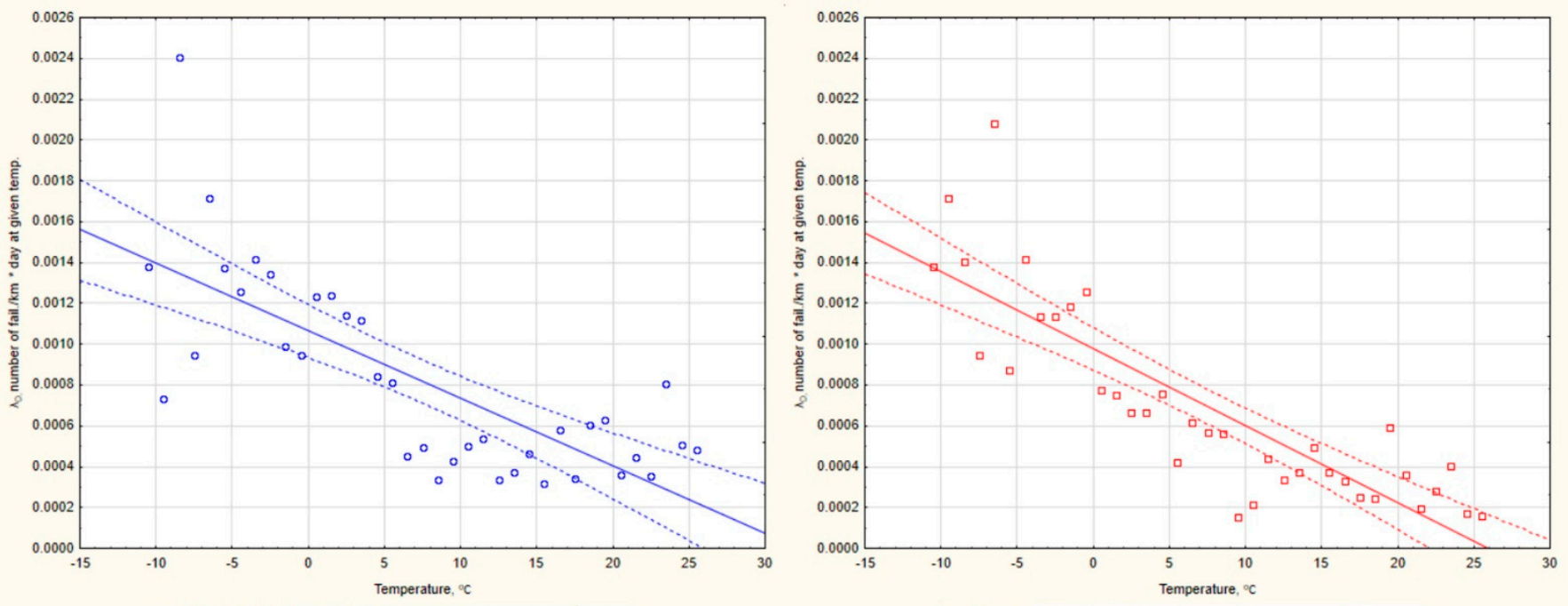

a $100 \mathrm{~mm}$ Temperature vs $100 \mathrm{~mm}: \mathrm{y}=0.0011-3.3023^{*} 10^{-5 *} ; ; r^{2}=0.5666$
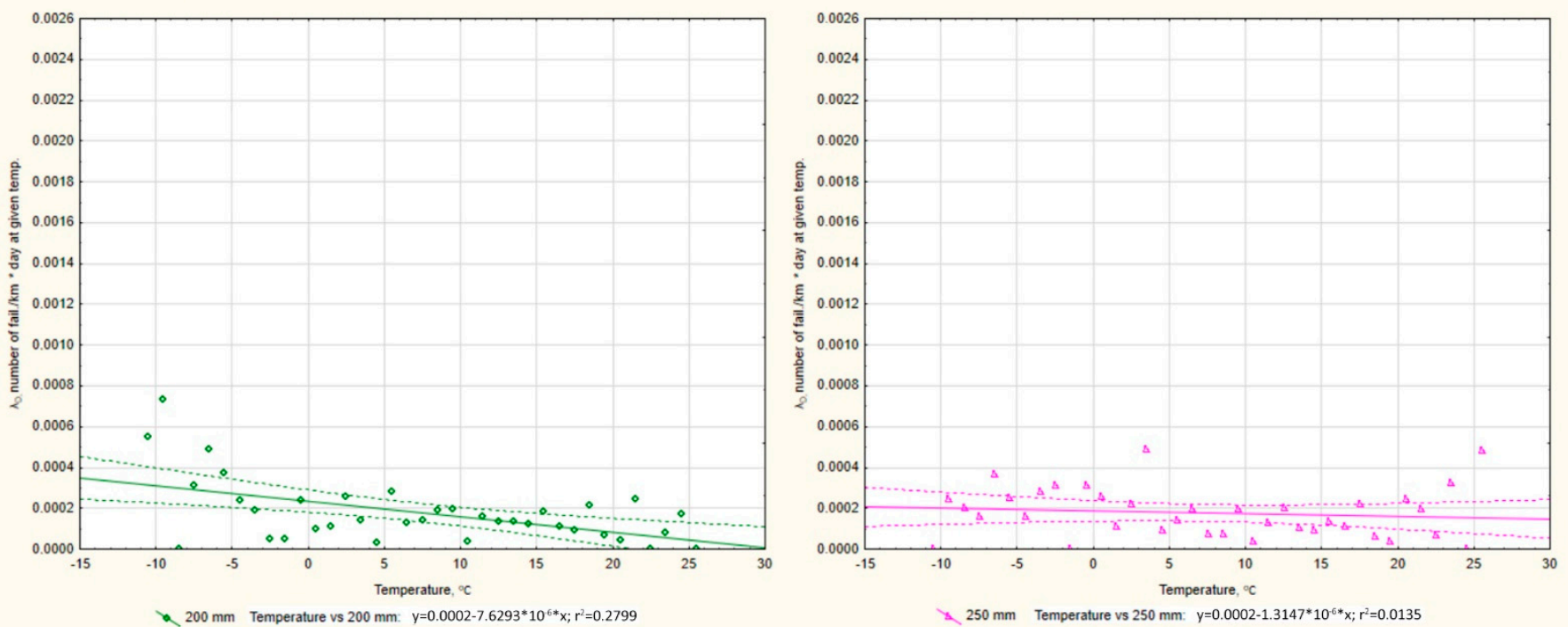

Figure 5. The correlation graphs for the failure rate of distribution network pipes with a given diameter (100-250 mm) and daily temperature. 

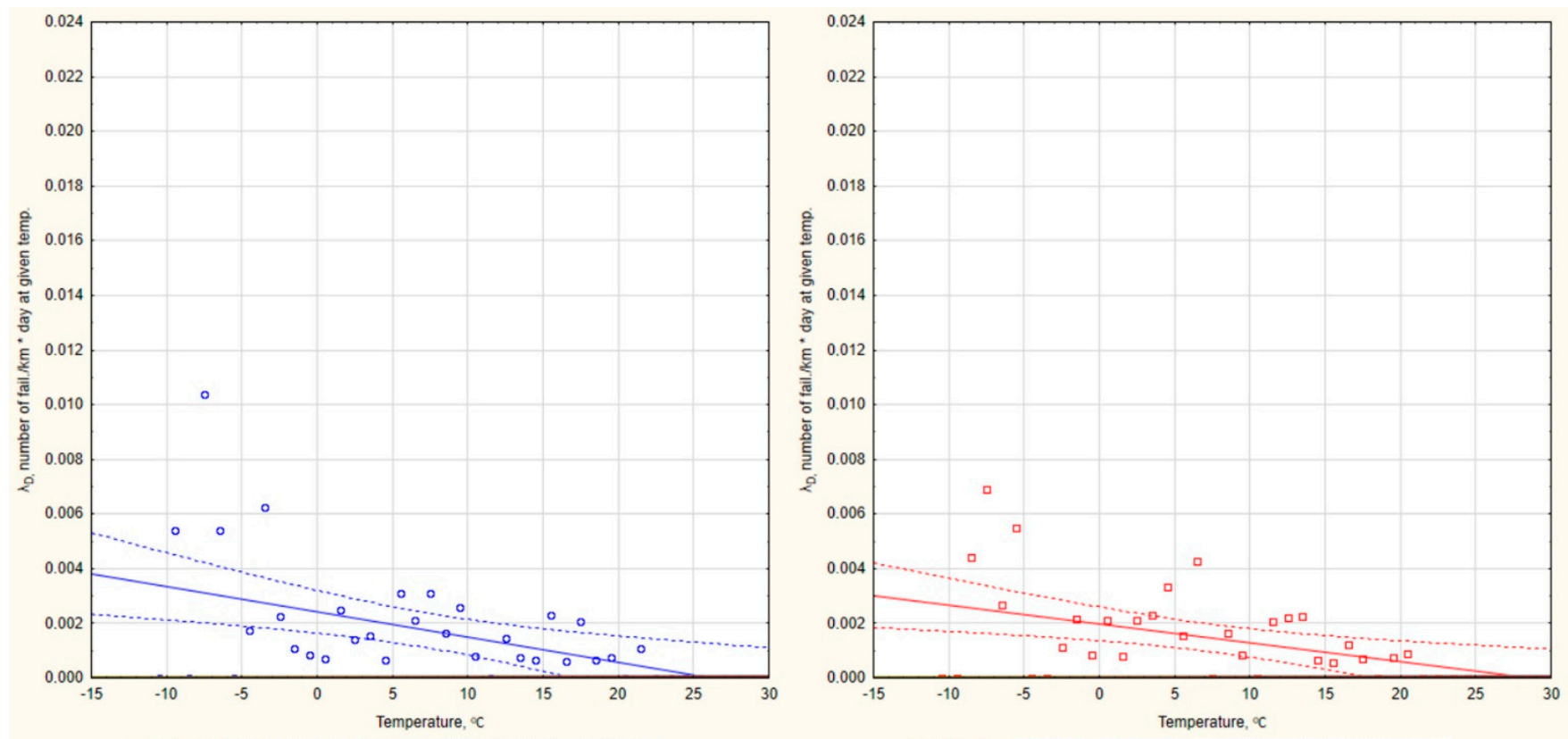

Q $300 \mathrm{~mm}$ Temperature vs $300 \mathrm{~mm}: \quad y=0.0024-9.311^{*} 10^{5 *} x ; r^{2}=0.2213$
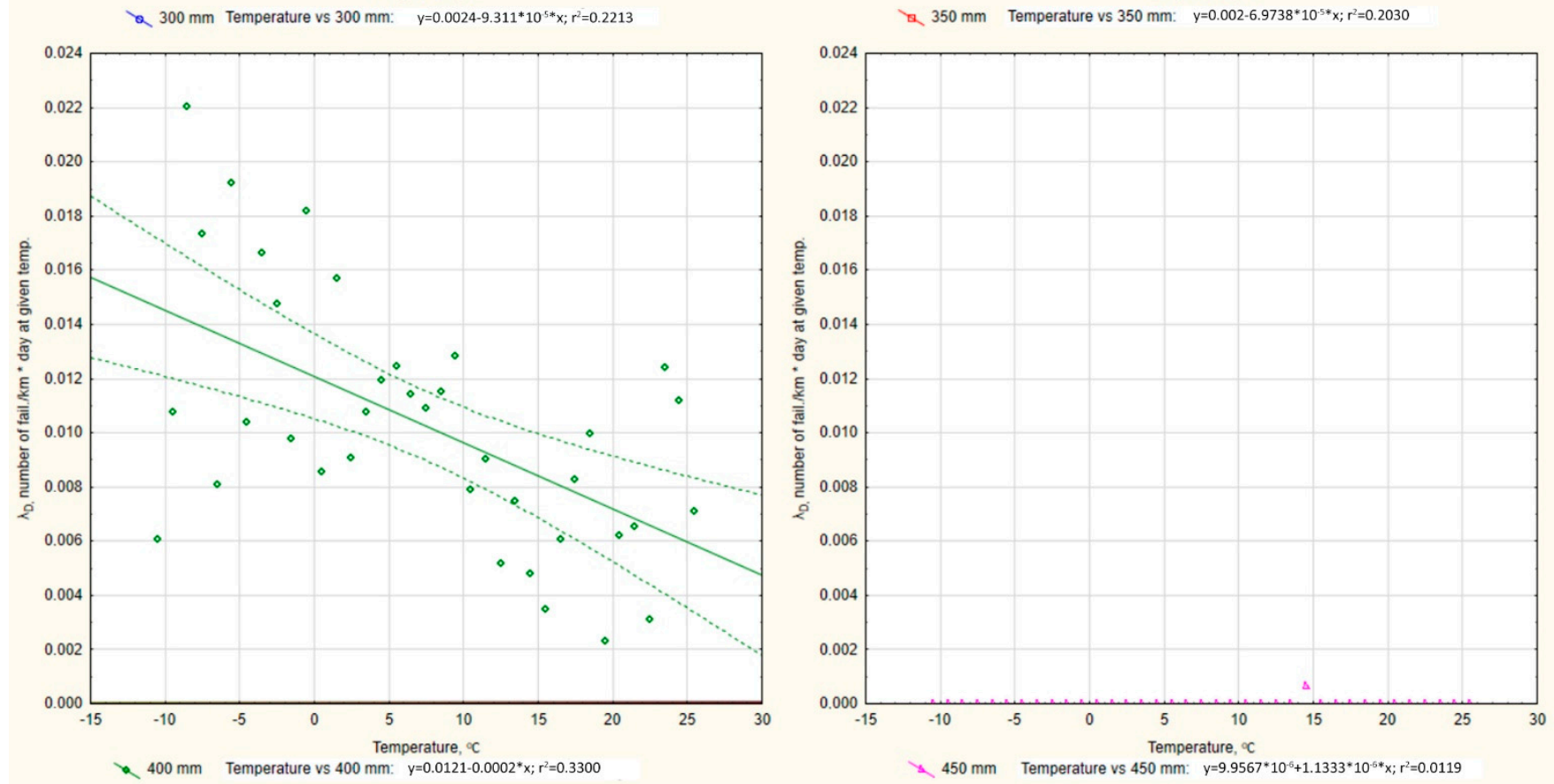

Figure 6. The correlation graphs for the failure rate of main network pipes with a given diameter (300-450 mm) and daily temperature. 

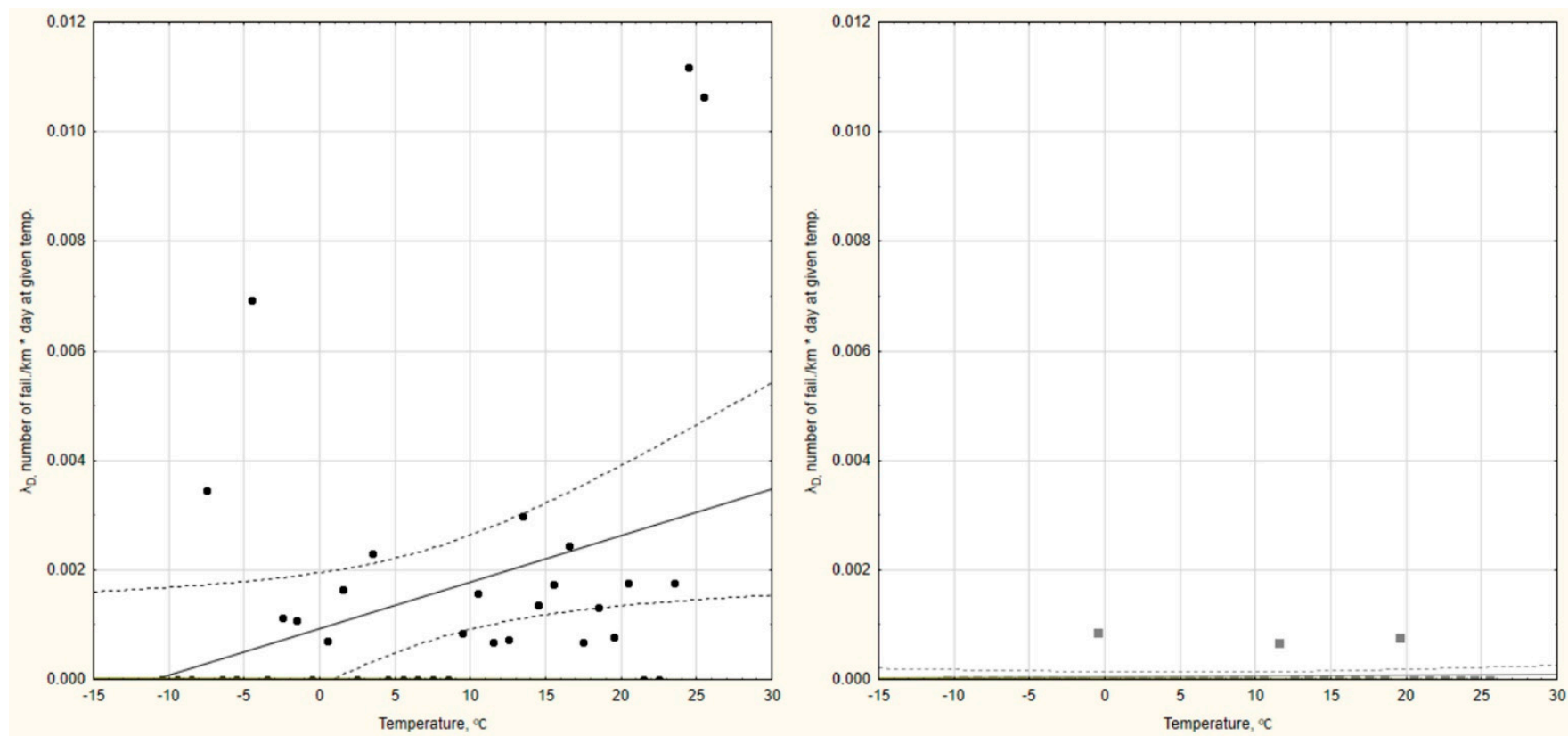

$500 \mathrm{~mm} \quad$ Temperature vs $500 \mathrm{~mm}: \quad \mathrm{y}=0.0009+8.5308^{*} 10^{5 *} x ; r^{2}=0.1217$

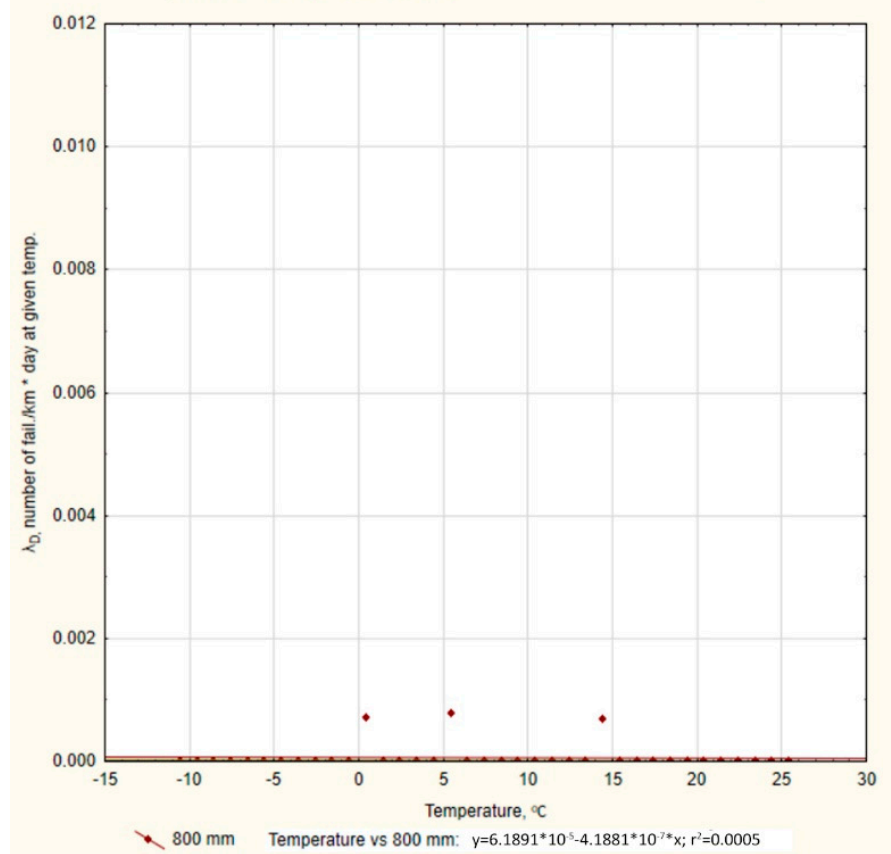

12. $600 \mathrm{~mm}$ Temperature vs $600 \mathrm{~mm}: \quad y=5.3865^{*} 10^{-5}+1.1927^{*} 10^{-6 *} x ; r^{2}=0.0036$

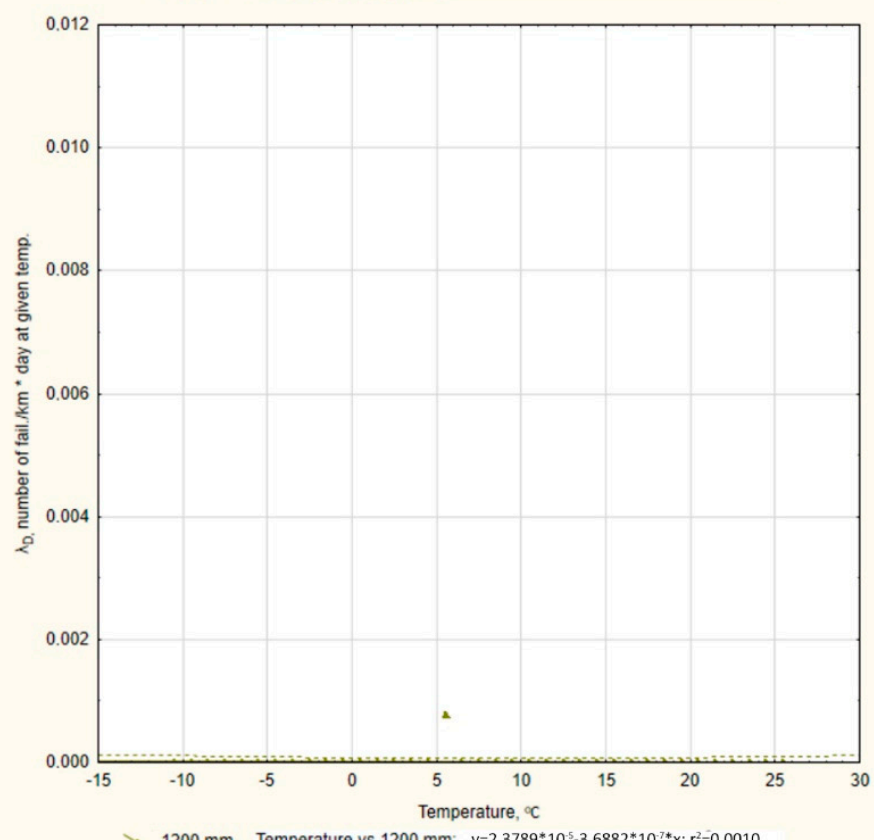

Figure 7. The correlation graphs for the failure rate of main network pipes with a given diameter (500-1200 mm) and daily temperature.

\section{Discussion}

The conducted literature studies show that the failure rate of the water supply network is influenced by many factors. There are external (environmental) factors, which include: climate, air temperature, ground temperature, ground freezing depth, tap water temperature, soil and groundwater conditions, groundwater corrosivity, etc. The second group of factors influencing the failure rate of the water supply network are internal factors related to the process of designing, construction and system operation, these are: pipe material, pipe diameter, pressure in the water supply network, flow value, quality of the network design, and construction and the quality of carried out pipe repairs. The paper presents the effect of negative daily temperatures on the failure rate of the water supply network. This factor is one of the most frequently studied factors affecting the failure 
rate of water supply systems. The study includes a comprehensive analysis taking into account the material and diameter of the pipe as well as the cause of the failure depending on the effect of negative temperatures. The research was carried out on operational data covering the years 2004-2018 for the water supply system in a city located in south-eastern Poland. The results confirm the thesis that in the case of negative temperatures, a bigger failure rate of the water supply system is observed. The obtained correlation coefficient between the failure rate and the daily temperature at the level of -0.787 confirms a strong correlation between the examined variables with a confidence level of $95.0 \%$. According to the presented linear regression model, the value of the failure rate increases by the value of 0.0163 damage/day with a temperature drop of $1{ }^{\circ} \mathrm{C}$. In the examined system, the highest values of the failure rate were observed for cast iron pipes ( $\lambda_{\text {Mavg }}=0.0031$ failure $/ \mathrm{km}$ day). The determined relationship between the failure rate and the daily temperature in the case of cast iron pipes is very strong (Pearson correlation coefficient $R=-0.924$ ). For pipes made of $\mathrm{AC}$, the second largest value of the failure rate was obtained $\left(\lambda_{\text {Mavg }}=0.0017\right.$ failure $/ \mathrm{km}$ day). However, due to the content of asbestos, these lines are successively replaced, and currently they stand for about $0.3 \%$ of all pipes in the system, and their high failure rates have little impact on the failure rate of the entire system. For steel pipes, a weak relationship $(R=0.299)$ was found between the daily temperature and the failure rate. The positive correlation coefficient value also proves that along with the temperature increase, the failure rate of steel pipes increases (mainly due to corrosion). Pipes made of plastics materials - PE and PVC - are characterized by low values of the damage intensity index on the average level for PE- $\lambda_{\text {Mavg }}=0.0002$ failure $/ \mathrm{km}$ day, and for PVC- $\lambda_{\text {Mavg }}=0.0001$ failure $/ \mathrm{km}$ day. For PE pipes, the existence of a moderate negative correlation $(R=-0.558)$ was shown, where an increase in the failure rate is observed when the temperature drops. For PVC pipes, the existence of a weak positive relationship $(R=0.349)$ was found, where the increase in the failure rate is observed with the temperature increase. It has been shown that for pipes made of plastic, the failure rate values are approximately 20 times lower than for cast iron pipes and 8 times lower than for steel pipes. The pipes in the analyzed system failed most often due to corrosion $\left(\lambda_{\text {Cavg }}=0.36\right.$ failure/day) and unsealing $\left(\lambda_{\text {Cavg }}=0.27\right.$ failure/day). Failures due to breakage and crack were less frequent $\left(\lambda_{\text {Cavg }}=0.10\right.$ failure $/$ day for a breakage and $\lambda_{\text {Cavg }}=0.05$ failure $/$ day for a crack). For unsealing, the existence of a strong relationship $(R=-0.899)$ was demonstrated between the daily temperature and the value of the failure rate. Similarly, for the breakage, the existence of a strong relationship $(R=-0.786)$ between the examined variables was shown. The negative value of the correlation shows that with the temperature decrease, the failure rate due to unsealing and breakage increases. For a crack, the values of the failure rate at negative temperatures are above the average, but the difference is not as large as in the case of unsealing and breakage. In the case of corrosion, the values of the failure rate at negative temperatures are similar to those at positive temperatures. For cracks and corrosion, no correlation was found between the daily temperature and the value of the failure rate at a given confidence level of $95.0 \%$. It has been shown that the mechanical causes of failure (in particular, unsealing and breakage) occur more frequently at negative temperatures. This is mainly related to the stresses appearing in the ground during its freezing and thawing. The study also presents an analysis of the dependence of water supply network failures depending on the diameter and daily temperature divided into the type of network: water supply connections, distribution network, and main network. Among the water supply connections, pipes with a diameter of 32,50 , and $80 \mathrm{~mm}\left(\lambda_{\text {Davg } 80 \mathrm{~mm}}=0.0016\right.$ failure $/ \mathrm{km}$ day, $\lambda_{\text {Davg } 50 \mathrm{~mm}}=0.0015$ failure $/ \mathrm{km}$ day, $\lambda_{\text {Davg } 32 \mathrm{~mm}}=0.0015$ failure $/ \mathrm{km}$ day), in the distribution network these were pipes with a diameter of 100 and $150 \mathrm{~mm}\left(\lambda_{\text {Davg }} 100 \mathrm{~mm}\right.$ $=0.0008$ failure $/ \mathrm{km}$ day, $\lambda_{\text {Davg } 150 \mathrm{~mm}}=0.0007$ failure $/ \mathrm{km}$ day) and in the main network pipes with a diameter of 300,400 , and $500 \mathrm{~mm}\left(\lambda_{\text {Davg } 400 \mathrm{~mm}}=0.01025\right.$ failure $/ \mathrm{km}$ day, $\lambda_{\text {Davg } 300 \mathrm{~mm}}=0.00173$ failure $/ \mathrm{km}$ day, $\lambda_{\text {Davg } 500 \mathrm{~mm}}=0.00156$ failure $/ \mathrm{km}$ day). The existence of a negative correlation between the daily temperature and the value of the failure rate for diameters of $80,100,150,200,300,350,400 \mathrm{~mm}$ and a positive correlation for diam- 
eters of 25 and $500 \mathrm{~mm}$ was demonstrated. For the other diameters, no dependence was shown with the adopted confidence level of $95.0 \%$. Among the water supply connections, the highest correlation coefficient was obtained for the diameter of $80 \mathrm{~mm}(R=-0.580)$, which shows a moderate strength of the relationship between the daily temperature and the failure rate. For the distribution network, the highest correlation coefficient was obtained for a diameter of $150 \mathrm{~mm}(R=-0.852)$, which shows a strong relationship between the examined variables. In the case of the main network, the highest correlation coefficient ( $R=-0.574)$ was obtained for the diameter of $400 \mathrm{~mm}$, which defines the relationship between the examined variables as moderate. The differences in the value of the failure rate for individual diameters depend on several factors, including type of network, material from which the pipe is made, construction methods, quality of construction works, and proper operation. The research shows that at negative temperatures, the highest values of failure rate are observed for diameters in the main network of 400, 350, $300 \mathrm{~mm}$ and for diameters of 150 and $100 \mathrm{~mm}$ in the distribution network. During repair works of these pipes, attention should be paid to the quality of the materials used and the repair work in order to eliminate internal factors affecting the failure rate of the water supply network.

\section{Conclusions}

The failure rate of the water supply network is influenced by many factors, including: climate, air temperature, ground temperature, ground freezing depth, water supply temperature, soil and water conditions, groundwater corrosivity, pipe material, pipe diameter, pressure in the water supply network, quality of design and construction of the network. The paper contains a comprehensive analysis of the influence of negative daily temperatures on the failure rate of the water supply network, taking into account the material and diameter of the pipes and the cause of the failure. The research was carried out on operational data covering the years 2004-2018 for the water supply system in a city located in south-eastern Poland. The existence of a relationship between the examined failure rates and the daily temperature was demonstrated. An increase in the failure rate of the water supply system is observed with the temperature decrease. In order to reduce the influence of temperature on the failure rate of the water supply network, plastic materials such as PE or PVC should be used, and the cast iron, steel, and AC pipes should be gradually replaced in the water distribution system. The use of plastics materials will also reduce the most common cause of failure, which is corrosion of the pipes. Failures due to unsealing of pipes are also a big problem, so more attention to the correct operation of the network (appropriate pressure and flow values) and to the proper quality of construction works in the case of new pipes and the correct performance of repair works on the existing pipes should be paid. Proper preparation of the excavation base and backfilling of the pipes or increasing the use of trenchless methods during works on the construction, repair, or development of the network will reduce the failure rate of pipes, especially with diameters of 100, 150, 300,350 , and $400 \mathrm{~mm}$, for which the highest values of failure rate are currently observed. These results can be used by water supply companies when planning the development and modernization of the existing network pipes in order to reduce the factors affecting the failure rate of the water supply network related to the negative daily temperatures.

Supplementary Materials: The following are available online at https: / www.mdpi.com/article / 10.3390/resources10090089/s1, Table S1: Failure rate values depending on the daily temperature, Table S2: Failure rate values depending on the daily temperature and pipes material, Table S3: Failure rate values depending on the daily temperature and the cause of the failure, Table S4: Failure rate values depending on the daily temperature and the pipe diameter for water supply connections (25 mm-80 mm), Table S5: Failure rate values depending on the daily temperature and the pipe diameter for the distribution network (100 mm-250 mm), Table S6: Failure rate values depending on the daily temperature and the pipe diameter for the main network (300 mm-450 mm), Table S7: Failure rate values depending on the daily temperature and the pipe diameter for the main network (500 mm-1200 mm). 
Author Contributions: All authors (J.Ż., K.B. and D.K.) equally contributed to the development of this manuscript. All authors have read and agreed to the published version of the manuscript.

Funding: This research received no external funding.

Institutional Review Board Statement: Not applicable.

Informed Consent Statement: Not applicable.

Data Availability Statement: 3rd Party Data. Restrictions apply to the availability of these data. Data was obtained from local water company and are available from the authors with the permission of data provider.

Acknowledgments: We thank the reviewers for their feedback, which helped to improve the quality of the manuscript.

Conflicts of Interest: The authors declare no conflict of interest.

\section{References}

1. Szpak, D.; Tchórzewska-Cieślak, B. The Use of Grey Systems Theory to Analyze the Water Supply Systems Safety. Water Resour. Manag. 2019, 33, 4141-4155. [CrossRef]

2. Pietrucha-Urbanik, K.; Tchórzewska-Cieślak, B.; Eid, M. Water network-failure data assessment. Energies 2020, 13, 2990. [CrossRef]

3. Pietrucha-Urbanik, K.; Tchórzewska-Cieślak, B. Failure risk assessment in water network in terms of planning renewals-A case study of the exemplary water supply system. Water Pract. Technol. 2017, 12, 274-286. [CrossRef]

4. Szpak, D. Method for determining the probability of a lack of water supply to consumers. Energies 2020, 13, 5361. [CrossRef]

5. Szpak, D.; Piegdon, I. Identification of Failure Causes in the Water Supply Network. J. Konbin. 2019, 49, 283-300. [CrossRef]

6. Gwoździej-Mazur, J.; Świętochowski, K. Failure frequency of water supply networks in the Podlaskie voivodeship. In Proceedings of the 11th Conference on Interdisciplinary Problems in Environmental Protection and Engineering EKO-DOK, Polanica-Zdrój, Poland, 8-10 April 2019; Volume 100, p. 00025.

7. Pietrucha-Urbanik, K. Failure analysis and assessment on the exemplary water supply network. Eng. Fail. Anal. 2015, 57, 137-142. [CrossRef]

8. Wiśniowska, E.; Włodarczyk-Makuła, M.; Rak, J.; Tchórzewska-Cieślak, B. Estimation of potential health and environmental risk associated with the presence of micropollutants in water intakes located in rural areas. Desalin. Water Treat. 2020, 199, 339-351. [CrossRef]

9. Tchórzewska-Cieślak, B.; Pietrucha-Urbanik, K.; Papciak, D. An approach to estimating water quality changes in water distribution systems using fault tree analysis. Resources 2019, 8, 162. [CrossRef]

10. Foster, T.; Willetts, J.; Lane, M.; Thomson, P.; Katuva, J.; Hope, R. Risk factors associated with rural water supply failure: A 30-year retrospective study of handpumps on the south coast of Kenya. Sci. Total Environ. 2018, 626, 156-164. [CrossRef] [PubMed]

11. Piegdon, I.; Tchórzewska-Cieślak, B. Seasonality of water supply network failure in the aspect of water supply safety. In Proceedings of the 10th Conference on Interdisciplinary Problems in Environmental Protection and Engineering EKO-DOK 2018, Polanica Zdrój, Poland, 16-18 April 2018; Volume 44, p. 00140.

12. Kuliczkowska, E.; Kuliczkowski, A.; Tchórzewska-Cieślak, B. The structural integrity of water pipelines by considering the different loads. Eng. Fail. Anal. 2020, 118, 104932. [CrossRef]

13. Boryczko, K.; Pasierb, A. Method for forecasting the failure rate index of water pipelines. In Environmental Engineering V; CRC Press: London, UK, 2017.

14. Kapelan, Z.; Giustolisi, O.; Savic, D. Risk assessment of water supply interruptions due to mechanical pipe failures. In Proceedings of the 9th Computing and Control for the Water Industry (CCWI2007) and the Sustainable Urban Water Management (SUWM) Conferences, Leicester, UK, 3-5 September 2007.

15. Kubat, B.; Kwietniewski, M. Modeling and visualization of failure rate of a water supply network using the regression method and gis. Desalin. Water Treat. 2020, 186, 19-28. [CrossRef]

16. Bruaset, S.; Sægrov, S. An analysis of the potential impact of climate change on the structural reliability of drinking water pipes in cold climate regions. Water 2018, 10, 411. [CrossRef]

17. Wols, B.A.; Van Thienen, P. Impact of weather conditions on pipe failure: A statistical analysis. J. Water Supply Res. Technol. 2014, 63, 212-223. [CrossRef]

18. Wols, B.A.; Vogelaar, A.; Moerman, A.; Raterman, B. Effects of weather conditions on drinking water distribution pipe failures in the Netherlands. Water Sci. Technol. Water Supply 2019, 19, 404-416. [CrossRef]

19. Hotlos, H. Quantitative assessment of the influence of water pressure on the reliability of water-pipe networks in service. Environ. Prot. Eng. 2010, 36, 103-112.

20. Friedl, F.; Schrotter, S.; Kogseder, B.; Fuch-Hanusch, D. Early failure detection model for water mains due to seasonal climatic impacts. In Proceedings of the World Environmental and Water Resources Congress 2012: Crossing Boundaries, Albuquerque, NM, USA, 20-24 May 2012. 
21. Fuchs-Hanusch, D.; Friedl, F.; Scheucher, R.; Kogseder, B.; Muschalla, D. Effect of seasonal climatic variance on water main failure frequencies in moderate climate regions. Water Supply 2013, 13, 435-446. [CrossRef]

22. Gould, S.J.F.; Boulaire, F.A.; Burn, S.; Zhao, X.L.; Kodikara, J.K. Seasonal factors influencing the failure of buried water reticulation pipes. Water Sci. Technol. 2011, 63, 2692-2699. [CrossRef]

23. Wols, B.A.; van Thienen, P. Modelling the effect of climate change induced soil settling on drinking water distribution pipes. Comput. Geotech. 2014, 55, 240-247. [CrossRef]

24. Zywiec, J.; Piegdon, I.; Tchórzewska-Cieślak, B. Failure analysis of the water supply network in the aspect of climate changes on the example of the central and eastern europe region. Sustainability 2019, 11, 6886. [CrossRef]

25. Rajani, B.; Tesfamariam, S. Estimating time to failure of cast-iron water mains. Proc. Inst. Civ. Eng. Water Manag. 2007, 160, 83-88. [CrossRef]

26. Kakoudakis, K.; Farmani, R.; Butler, D. Pipeline failure prediction in water distribution networks using weather conditions as explanatory factors. J. Hydroinf. 2018, 20, 1191-1200. [CrossRef]

27. Wols, B.A.; Van Daal, K.; Van Thienen, P. Effects of climate change on drinking water distribution network integrity: Predicting pipe failure resulting from differential soil settlement. Procedia Eng. 2014, 70, 1726-1734. [CrossRef]

28. Sobczyk, M. Statystyka; Wydawnictwo Naukowe PWN: Warsaw, Poland, 2016. (In Polish) 